\title{
SOBREVIVENTE, OUVINTE E A TENTATIVA DE SUPERAÇÃO DO TRAUMA: OS PERSONAGENS SOL NAZERMAN E MARILYN \\ BIRCHFIELD NO ROMANCE THE PAWNBROKER, DE EDWARD LEWIS WALLANT
}

\author{
Vanderléia de Andrade Haiski ${ }^{1}$
}

Resumo: Este artigo tem por objetivo analisar os personagens Sol Nazerman e Marilyn Birchfield nos papéis de sobrevivente e ouvinte, respectivamente, no romance The Pawnbroker. Este romance foi escrito pelo judeu-americano Edward Lewis Wallant em 1961 e conta a história de um sobrevivente do Holocausto que passou pelos horrores da guerra e assistiu a morte de toda a sua família. O personagem central, Sol Nazerman, é um homem que vive atormentado pelo seu passado de violência e de dor. Neste estudo, é destacada a importância da narrativa para a superação dos traumas bem como o papel do ouvinte nesse processo. Para o embasamento da proposta elencada, busca-se respaldo em autores como Dori Laub, Walter Benjamin, Sigmund Freud e Bruno Bettelheim.

Palavras-chave: Holocausto. Trauma. Sobrevivente. Ouvinte. Superação.

\begin{abstract}
This article aims to analyze the characters Sol Nazerman and Marilyn Birchfield in the roles of survivor and listener, respectively, in the novel The Pawnbroker. This book was written by the American Jewish Edward Lewis Wallant in 1961 and it tells the story of a Holocaust survivor who went through the horrors of the Second World War and witnessed the death of his whole family. The main character, Sol Nazerman, is a man who is tormented by his past of violence and pain. In this study, we highlighted the importance of the narrative to overcome the trauma and the role of the listener during this process. Dori Laub, Walter Benjamin, Sigmund Freud, and Bruno Bettelheim, among others, are the main scholars who inform the present approach.
\end{abstract}

Keywords: Holocaust. Trauma. Survivor. Listener. Overcoming.

"A ficção dá olhos ao narrador horrorizado. Olhos para ver e para chorar. [...] [T]alvez haja crimes que não se devam esquecer, vítimas cujo sofrimento peça menos vingança do que narrativa.”

(Paul Ricoeur)

\footnotetext{
1 Mestre em Letras: Literatura Comparada pela Universidade Regional Integrada do Alto Uruguai e das Missões - URI/ FW. E-mail: vanderleiadeandrade@hotmail.com
} 
A linguagem é um sistema de signos de que os seres humanos fazem uso a fim de produzir e atribuir sentidos aos fatos. Ela integra as relações humanas e, por meio dela, o indivíduo pode organizar e estruturar seu pensamento, comunicar suas experiências, seus sentimentos e suas inquietações, suas ideias e seus valores e, também, transmitir o conhecimento adquirido no decorrer de sua existência. Além do mais, é o reflexo do indivíduo ou de uma sociedade, na medida em que, através dela, é representado o comportamento social, cultural, moral e ético, além de ser possível perpetuar a história através da oralidade e/ou da escrita. O mundo, sem a linguagem, seria um mundo sem passado, com um presente vazio e sem perspectiva de futuro.

Este artigo tem por objetivo verificar como a narrativa pode auxiliar no processo de superação dos traumas em pessoas que foram vítimas de eventos violentos, como o Holocausto, a partir dos personagens Sol Nazerman e Marilyn Birchfield, nos papéis de sobrevivente e ouvinte. No decorrer do romance The Pawnbroker (1961) é evidenciada a relação entre superação dos traumas do personagem central e a narrativa. Luiz Costa Lima define a narrativa como "o estabelecimento de uma organização temporal, através de que o diverso, o irregular e o acidental entram em uma ordem; ordem que não é anterior ao ato da escrita mas coincide com ela; que é pois constitutiva de seu objeto" (LIMA, 1989, p.17). Walter Benjamin, por sua vez, em $O$ narrador, afirma que a origem a qual recorrem os narradores é a experiência transmitida de uma pessoa a outra e que, tratando-se da natureza da narrativa, "[e]la tem sempre em si, às vezes de forma latente, uma dimensão utilitária. Essa utilidade pode consistir seja num ensinamento moral, seja numa sugestão prática, seja num provérbio ou numa norma de vida - de qualquer maneira, o narrador é um homem que sabe dar conselhos" (BENJAMIN, 1994, p. 198). Como se observa nos apontamentos de Costa Lima e Benjamin, a narrativa desenvolve funções primordiais a todos os seres humanos.

Nesse sentido, a linguagem tem uma função importante para indivíduos que passaram por uma situação traumática. Para as pessoas que vivenciaram um episódio violento, a linguagem possibilita conferir significação a tais experiências e, por intermédio do seu conjunto de normas, pode conduzir a uma organização coerente e racional dos fatos envolvidos. Logo, facilita ao sujeito constituir seus pensamentos e vivências e, por conseguinte, traduzi-los e comunicá-los aos ouvintes ou aos leitores. Afora isso, a linguagem, tanto na sua forma escrita quanto oral, é uma maneira de registrar a memória, seja ela individual ou coletiva, para que o passado não se perca no esquecimento e para que outras pessoas, de diferentes lugares e culturas, em tempos próximos ou distantes, tenham acesso a tais registros.

A propósito, Benjamin, ainda no referido texto, declara que a narrativa não é uma experiência superficial, pois "[e]la mergulha a coisa na vida do narrador para em seguida retirá-la dele" (BENJAMIN, 1994, p. 205). Além disso, as histórias do narrador remetem a uma narrativa que se dá espontaneamente, já que narrar implica a capacidade de trocar experiências. Contudo, essa capacidade nem sempre é desenvolvida com êxito após experiências traumáticas, pois, para narrar tais acontecimentos, o sujeito, na maioria das vezes, sente dificuldade em encontrar nas palavras uma carga semântica que dê conta de forma satisfatória da representação desses eventos. Todavia, superada essa condição, juntamente com a narrativa, surge a possibilidade de algumas transformações. 
Essa ideia de que um acontecimento doloroso pode ser superado por meio de uma narrativa pode ser atestada a partir de um pequeno texto escrito por Benjamin intitulado Conto e cura. Nele, o filósofo alemão relata sobre a mãe que conta histórias para a criança doente e, logo em seguida, sugere que a narração teria o poder de curar. Aliás, o autor propõe que o próprio "relato que o paciente faz ao médico no início do tratamento pode se tornar o começo de um processo curativo" (BENJAMIN, 1995, p. 269). Surge, então, a hipótese de que a narração formaria o clima propício e a condição mais favorável de muitas curas. Nesse sentido, tais pressupostos teóricos respaldam a análise de obras ficcionais, como o romance The Pawnbroker, e a relação estabelecida entre os personagens.

The Pawnbroker, de Edward Lewis Wallant, foi publicado em 1961 e consiste numa obra da literatura judaica reconhecida em diferentes partes do mundo, principalmente nos Estados Unidos, país onde seu autor estabeleceu residência. O livro tem sido objeto de estudo sob diferentes enfoques em dissertações, teses e ensaios acadêmicos ${ }^{2}$. O romance de Wallant também é mencionado em textos sobre a literatura judaico-americana como, por exemplo, The Jewish American Novel, de Philippe Codde, American Jewish Fiction, de Josh Lambert, e Contemporary Jewish-American Novelists: A Bio-Critical Sourcebook, de Joel Shatzky e Michael Taub. Diferentemente do que acontece no Brasil, no cenário norte-americano, a literatura judaica, de um modo geral, há algum tempo, já tem o seu lugar estabelecido.

Narrado em terceira pessoa, The Pawnbroker está dividido em 27 capítulos, no decorrer dos quais o narrador revela com detalhes as características, os sentimentos e a história dos diversos personagens desse romance. O personagem principal, Sol Nazerman, é um sujeito traumatizado pela experiência do Holocausto e tem como uma de suas principais características a frieza emocional. Logo no início do romance, muitas passagens o caracterizam como uma pessoa insensível emocionalmente, que não demonstra interesse em manter vínculos afetivos e que é indiferente aos que o cercam. Na descrição do narrador, "Sol não tinha amigos"3 (WALLANT, 1961, p. 13), tinha "seus olhos cobertos de tédio"4 (p.5) e era um homem "verdadeiramente feito de pedra" (p. 17). O próprio protagonista, ao ser questionado por um cliente sobre a sua frieza, responde que ele "[n]ão tem coração"6 (WALLANT, 1961, p. 15), confirmando a percepção dos indivíduos que se aproximavam dele.

Além de ser uma vítima dos horrores do regime totalitário de Hitler, Sol testemunhou fatos terríveis demais para concebê-los: viu seu melhor amigo ser eletrocutado, foi forçado a

\footnotetext{
2 Convém mencionar os seguintes trabalhos a respeito do aludido romance: as teses Representing Holocaust Trauma: The Pawnbroker and Everything is Illuminated, de Raïssa Verstryinge; The Reconstruction of Jewish Male Identity in Edward Lewis Wallant's The Pawnbroker, Isaac Bashevis Singer's Enemies: a Love Story, and Saul Bellow's Mr. Sammler's Planet, de Malgorzata Spiz, e The Holocaust in Movies, de Dora Trif, bem como os artigos The Pawnbroker: Holocaust, Memory and Film, de Richard Stites; Teach me Gold: Pedagogy and Memory in The Pawnbroker, de Alan Rosen, e My Holocaust is not your Holocaust: Facing Black and Jewish Experience in The Pawnbroker, Higher Ground and The Nature of Blood, de Wendy Zieler.

3 Todas as traduções são de minha autoria. Traduzido do original: "Sol had no friends".

4 Traduzido do original: "his eyes lidded with boredom".

5 Traduzido do original: "[t]ruly was made of stone".

6 Traduzido do original: "No heart".
} 
testemunhar sua esposa ser estuprada pelos soldados nazistas, além de encontrar o corpo de sua filhinha perfurado e pendurado em um gancho. Assim, Nazerman sente-se deslocado em uma sociedade onde pessoas consideradas "normais" poderiam cometer atos bárbaros. Em virtude disso, em uma conversa com seu ambicioso assistente na loja de penhores, Jesus Ortiz, ele afirma não depositar confiança em nada e em ninguém:

“Eu não confio em Deus ou políticos, ou jornais, ou músicas ou artes. Eu não confio em sorrisos, ou roupas ou edifícios ou paisagens ou cheiros". [...] "Eu não confio em nomes. Eu não confio em expressões ou cores ou em sentir a textura”. [...] "Mas, acima de tudo, eu não confio em pessoas e nos seus discursos, pois eles têm criado o inferno com aquele discurso, pois eles têm provado não merecer existir pelo que eles são"7 (WALLANT, 1961, p. 114-115).

Sol expressa sua desilusão quando declara os vários segmentos em que não confia. Primeiramente, demonstra sua descrença em Deus, negando a sua própria religião judaica. Além disso, para o protagonista, homens "normais" não são confiáveis, pois foram eles que assassinaram a sua família e, não importava onde estivesse, como saber se as pessoas que o cercavam não agiriam de modo cruel novamente? A declaração de Nazerman expõe o poder dos seres humanos em dominarem uns aos outros, a dissimulação através de discursos para acobertar seus atos bárbaros e a insensibilidade diante do próximo. Com a tentativa do Holocausto de anular sentimentos, emoções, sensações, enfim, o que há de mais humano em um indivíduo, Sol perde a sua sensibilidade e confiança naquilo que o cerca.

As características comportamentais de Nazerman têm suas motivações nos vários episódios traumáticos que foi obrigado a viver. Assim, a sua frieza emocional, o distanciamento que preferiu manter em relação às pessoas à sua volta, o abandono da sua religião e mesmo do seu idioma funcionam como estratégias a que ele próprio aderiu como forma de não vivenciar pela recordação os horrores do passado. Se o trauma define-se como uma ferida não cicatrizada que incomoda a vítima, logo o fato de ele evitar, no seu dia a dia, certas lembranças que surgem em decorrência de outras torna-se algo justificável, pois tem em seu horizonte a possibilidade de um novo dano.

$\mathrm{Na}$ mesma ocasião, Jesus Ortiz pergunta se não há nada em que ele confia e, com seu olhar frio, Sol responde: "[t]alvez haja algo. [...] Dinheiro"8 (WALLANT, 1961, p. 115). A única coisa em que Sol ainda conseguia depositar um pouco de confiança era no dinheiro. Afora isso, nada mais tinha qualquer importância para ele, algo que o levou a enfatizar ao seu assistente: "[e]u tenho ensinado a você o credo do penhorista, Ortiz. O que mais há para saber!"9 (WALLANT, 1961, p. 115). Nazerman perdeu tudo o que tinha de valor e passou por todo o tipo de privação nos campos de concentração, o que explica sua confiança apenas no

\footnotetext{
7 Traduzido do original: “I do not trust God or politics or newspapers or music or art. I do not trust smiles or clothes or buildings or scenery or smells'. [...] 'I do not trust names. I do not trust expressions or colors or the feel of texture'. [...] 'But, most of all, I do not trust people and their talk, for they have created hell with that talk, for they have proved they do not deserve to exist for what they are"'.

8 Traduzido do original: "Perhaps there is something. [...] Money".

9 Traduzido do original: “I have taught you the Pawnbroker's Credo, Ortiz. What else is there to know!".
} 
dinheiro. Primeiramente, o dinheiro não é algo que possa morrer ou que possa traí-lo e é constantemente valioso. Além do mais, o dinheiro pode comprar comida, roupas, calçados, conforto e segurança, bens dos quais foi privado enquanto vítima do nazismo. Nesse sentido, o dinheiro dava a segurança de possuí-los novamente, evitando, desse modo, reviver o trauma causado por todas as privações sofridas.

Assim, envolvido por esse clima sombrio, o protagonista se torna uma pessoa que não demonstra emoções. Sol era incapaz de evidenciar medo, tristeza, compaixão, amor ou carinho, até mesmo em situações em que tais sentimentos deveriam aflorar naturalmente. Tamanha apatia conduzia as pessoas que tinham contato com ele a indagar sobre sua personalidade, a ponto de ser questionado: “[n]ão existe nenhuma emoção que restou em você? Digo, você não sente pena ou amor...” ${ }^{10}$ (WALLANT, 1961, p. 147). A mesma insensibilidade que predominou nos homens durante o horror do nazismo agora era parte do próprio sobrevivente e visivelmente clara para todos que o rodeavam.

A personalidade fria e rude de Nazerman é consonante com a ideia expressa por Theodor Adorno, em Educação após Auschwitz, de que, quando um indivíduo "é duro contra si mesmo, adquire o direito de sê-lo contra os demais e se vinga da dor que não teve a liberdade de demonstrar, que precisou reprimir" (ADORNO, 1994, p. 39). A dor e o medo não deveriam ser reprimidos, pois, quando um indivíduo se permite ter tanto medo quanto a realidade vivenciada fizer jus, maior a possibilidade de grande parte do efeito destrutivo do medo inconsciente e reprimido desaparecer (ADORNO, 1994, p. 39-40). Sol Nazerman reprime de forma veemente sua dor e suas angústias, e esse é um fardo que tenta carregar sozinho, sem compartilhar ou expressar nada do que se passa em seu interior. Essa é uma forma de autoproteção contra o sofrimento ou a dor psicológica e também consiste numa barreira emocional para manter as pessoas a uma distância segura.

Diferentemente do que sente em relação às pessoas com quem convive, o dinheiro é um elemento que traz segurança a Nazerman. Se as relações sociais trazem algum prejuízo ao protagonista, o dinheiro gera conforto e não se constitui numa ameaça a ele. Considerando as premissas freudianas, quando o sujeito é ameaçado por algo externo e seu mecanismo psíquico é de algum modo despertado, como estratégia de autopreservação, ele desloca ou substitui por outro o elemento que pode causar dor. Ademais, a reificação que caracteriza Nazerman opera por meio de respostas padronizadas, que negam a dimensão pessoal de sofrimento, oferecendo uma solução aparentemente prática para as suas consternações. É como se o protagonista buscasse um estilo de vida sem qualquer tipo de surpresa, pois isso poderia causar-lhe algum efeito nocivo.

A propósito, essas características acerca da personalidade de Nazerman contribuíram para conduzi-lo à profissão de penhorista. Após sobreviver ao Holocausto, ele se refugiou em Paris, na França, até conseguir o visto para ir aos Estados Unidos. Nazerman estudou na Polônia, possuía formação acadêmica e trabalhou como professor. Contudo, ainda na França, conheceu Albert Murillio, que lhe propôs a profissão de penhorista nos Estados Unidos. Nazerman era descrito como "um homem sem alianças"11 (WALLANT, 1961, p. 7), e isso

\footnotetext{
10 Traduzido do original: “'Are there no emotions left to you? I mean, don't you ever fell pity or love...”.

11 Traduzido do original: "a man with no allegiances".
} 
chamou a atenção de Murillio. Assim, ele fez o investimento na loja de penhores na qual Sol seria o gerente e também o proprietário, pelo menos na documentação. A parte financeira se mostrou bastante vantajosa para Nazerman, e ele não hesitou em aceitar a proposta, tampouco se preocupou sobre as origens do dinheiro de Murillio. Sua única preocupação foi que "eles deixassem sua privacidade inviolada"12 (WALLANT, 1961, p. 7). A busca por essa inviolabilidade tem a ver com o perfil de um sujeito reificado e traumatizado, uma vez que a reificação forja um comportamento padronizado em que a vítima se acomoda e, assim, não se sente inibida por situações que podem ser ameaçadoras à constituição de uma personalidade aparentemente íntegra.

$\mathrm{Na}$ loja de penhores que Nazerman passou a administrar, surgiam clientes com as mais diversas dificuldades, que desejavam penhorar seus bens por um período de tempo, por precisarem de dinheiro para suprir uma necessidade imediata. Porém, o penhorista se mostrava indiferente à necessidade alheia e sempre "sua voz fria [...] oferecia o mínimo"13 (WALLANT, 1961, p. 25) aos seus clientes pelo bem penhorado. Tem-se, por exemplo, o caso da senhora Harmon, entre outros, que, em meio à urgência de dinheiro devido ao baixo salário do marido, à educação da filha e ao alto custo dos remédios do filho deficiente, recorreu à loja de Nazerman para penhorar dois castiçais de prata. Contudo, mesmo diante da argumentação de Harmon, o penhorista ofereceu um valor muito inferior ao que era devido ao produto (WALLANT, 1961, p. 16-17). Isso demonstra a insensibilidade de Nazerman e, também, a falta de ética com que conduzia seu trabalho, obtendo grandes vantagens de seus clientes que, diante de uma situação adversa, acabavam aceitando o que lhes era oferecido. E mais, o penhorista tinha consciência de suas práticas tortuosas, pois ele afirma que "[n]a verdade, esta é uma área para ganho desonesto, também” ${ }^{14}$ (WALLANT, 1961, p. 74).

Afora o trauma, Nazerman não passou por um importante processo durante a perda de sua família: o luto. Ao perder sua família, "[e]le não ficou de luto nem pranteou por eles, porque ele tinha sido cauterizado de todas as coisas abstratas"15 (WALLANT, 1961, p. 91). Dessa forma, o protagonista vivia num estado de melancolia, como se observa, por exemplo, na seguinte descrição: "[e] os olhos atrás dos óculos estranhos estavam maiores e mais escuros, pensativo e cheio de uma melancolia tão profunda que quase parecia emitir um som"16 (WALLANT, 1961, p. 227).

As diferenças entre o luto e a melancolia foram estabelecidas por Sigmund Freud. Segundo o psicanalista, tanto o primeiro quanto a segunda são duas atitudes possíveis frente a uma experiência de perda. No entanto, enquanto no luto o objeto perdido pode ser substituído por outro após um determinado período de tempo; na melancolia, não ocorre essa possibilidade. O objeto de amor perdido não pode ser reestabelecido ou restituído (FREUD, 1996, p. 249-250). Assim, as perdas de Nazerman, incluindo-se aí a de sua família e a de seus

\footnotetext{
12 Traduzido do original: "they left his privacy inviolate".

13 Traduzido do original: "his cool voice [...] offered the very least".

14 Traduzido do original: "Actually, this is an area for dishonest profit, too".

15 Traduzido do original: "He did nor grieve or mourn them, because he had been cauterized of all abstracts things".

16 Traduzido do original: "And the eyes behind the weird glasses were larger and darker, brooding and full of a melancholy so profound that it almost seemed to emit a sound".
} 
amigos, por estarem vinculadas a um trauma, não pertencem ao passado, mas são da ordem do seu cotidiano. Com isso, o trauma, por ser um evento repetido, causaria no sujeito um sentimento de perda insuperável, algo que se filiaria ao estado melancólico. A melancolia de Nazerman concorre ainda para o seu desânimo, para o seu desinteresse pelas coisas ao seu redor, para a sua incapacidade de amar outras pessoas bem como para sua falta de autoestima. O narrador, nesse particular, afirma que "o seu espírito era como um velho terreiro de carnaval abandonado, em frangalhos, despedaçado, pobremente reconstruído e montado" 17 (WALLANT, 1961, p. 186). Assim, é evidente a degradação de sua autoestima, tanto no que se refere ao seu estado físico quanto ao seu estado psicológico.

A propósito, era comum Nazerman se depreciar diante dos que se aproximavam dele. Quando, por exemplo, Marilyn Birchfield tenta estabelecer uma relação mais próxima com o personagem, ele a adverte: "[e]u não sou um homem socialmente inclinado"18 (WALLANT, 1961, p. 103) e "[e]u não sou amistoso" ${ }^{19}$ (p. 103). Ele também não se sentia capaz de manter laços afetivos e, por esse motivo, tratava com frieza e indiferença sua família, isto é, sua irmã, seu cunhado e seus sobrinhos. Até mesmo para com sua amiga Tessie, também sobrevivente do Holocausto e para quem Nazerman despendia alguma ajuda financeira e visitava com frequência, ele não conseguia manter uma relação afetiva profunda, como demonstra a passagem a seguir, descrita pelo narrador durante uma relação sexual entre eles: "nada de amor verdadeiro ou ternura, mas, ao invés, aquela força imensamente poderosa de desespero e angústia mútua"20 (WALLANT, 1961, p. 62).

Nazerman tem uma grande dificuldade em estabelecer uma relação afetiva profunda com outras mulheres, uma vez que ele tinha uma esposa que amava muito e a perdeu num campo de concentração após vê-la passar por diversos sofrimentos. Isso demonstra o medo do protagonista de enfrentar uma nova perda e, consequentemente, retornar ao trauma já vivido. Nesse sentido, para se proteger, o sobrevivente evita instituir relações que possam criar as mesmas condições para a perda, que possam fazê-lo passar por sofrimento semelhante ao que passou no regime nazista e, sendo assim, procura não se envolver afetivamente com as mulheres que o cercam.

Contudo, conforme observação feita por Freud com base em alguns quadros clínicos de melancolia, em meio à marcante característica de insatisfação com o ego, torna-se proeminente o relato de pacientes sobre o temor de ficar pobre. Essa particularidade vai ao encontro da relação que Nazerman tinha com o dinheiro, pois, em meio a tanta desilusão e apatia, o único interesse que lhe restava era pelo dinheiro, ainda que desonesto, pois com ele pôde adquirir a casa confortável em que morava com a família de sua irmã e que lhe dava certa privacidade, financiava os estudos do sobrinho e, principalmente, o tornava independente de qualquer pessoa. Ao relatar ao seu assistente Ortiz sobre a importância do

\footnotetext{
17 Traduzido do original: "his spirit was like an old and shoddy carnival ground, threadbare, precariously tied and repaired".

18 Traduzido do original: "I am not a socially inclined man".

19 Traduzido do original: "I am not friendly".

20 Traduzido do original: "nothing of real love or tenderness, but, rather, that immensely stronger force of desperation and mutual anguish".
} 
dinheiro, o penhorista afirma que com ele é possível comprar muitas coisas, como "comida ou conforto, o alívio da dor, ou inclusive, às vezes... sim, às vezes ele pode comprar a sua própria vida"21 (WALLANT, 1961, p. 115). Todos esses aspectos demonstram que o sobrevivente do evento traumático do Holocausto vive num profundo estado de melancolia.

Nazerman não demonstrava interesse em compartilhar a sua dor e a sua angústia com quem quer que fosse. Ele não falava de seu passado, procurava manter ao máximo sua privacidade e vivia isolado em seu mundo interior. Nesse sentido, o protagonista reproduz um sentimento que imperava em muitos dos sobreviventes e testemunhas do Holocausto. A esse respeito afirma Hannah Arendt:

naquele mais sombrio dos tempos, dentro e fora da Alemanha, era particularmente forte, em face de uma realidade insuportável, a tentação de se desviar do mundo e de seu espaço público para uma vida interior, ou ainda simplesmente ignorar aquele mundo em favor de um mundo imaginário, "como deveria ser" ou como alguma vez fora (ARENDT, 2008, p. 27-28).

Nazerman desejava refugiar-se em sua vida interior, em seu mundo particular, e deixa isso evidente em uma conversa com Tessie. Quando indagado por ela sobre a possibilidade de livrar-se do inferno que vivenciara e ainda o cercava, declara: "[s]im, eu tenho escapado. Eu estou salvo dentro de mim mesmo. Eu tenho feito uma ordem para mim mesmo e ninguém pode perturbá-la"22 (WALLANT, 1961, p. 119). Diante da realidade insuportável que cercava os indivíduos nos tempos sombrios do Holocausto, era desejável enclausurar-se em um mundo particular, no qual, mesmo que imaginariamente, era possível fazer parte de uma sociedade "como deveria ser". Outra evidência de que Nazerman buscava refúgio no imaginário está na sua relação com a literatura, pois ele lia avidamente antes de dormir, visto que muitas de suas leituras evocavam certa familiaridade de algo que tinha sido apreciado e amado em tempos passados. Nazerman gostava das emoções evocadas na leitura, mas ele próprio não se envolvia emocionalmente, porquanto não eram permitidas exceções à sua invulnerabilidade (WALLANT, 1961, p. 97).

Diante da frieza emocional e do enclausuramento interior de Nazerman, destaca-se Marilyn Birchfield, que desempenha um papel fundamental no resgate da humanidade e na tentativa de superação do trauma do sobrevivente, pois cabe a ela o papel de ouvinte. Marilyn mudou-se de Springfield para Nova Iorque a fim de trabalhar no Youth Center, instituição que ajudava crianças de baixa renda, próximo à loja de penhores. Com aproximadamente 30 anos, era uma mulher simpática, sorridente, com uma aparência saudável e que falava com desenvoltura. $\mathrm{O}$ encontro de Marilyn com Nazerman ocorreu devido a uma iniciativa dela de apresentar-se aos comerciantes vizinhos a fim de arrecadar algum tipo de ajuda ou patrocínio para a sua instituição. Embora algo lhe tenha chamado atenção em Marilyn, o penhorista não a tratou com simpatia, tampouco aceitou qualquer tipo de envolvimento com a instituição de caridade. Apenas deu-lhe

\footnotetext{
21 Traduzido do original: "food or comfort, luxury, relief from pain, or even, sometimes... yes, it sometimes it can buy your life itself".

22 Traduzido do original: "Yes, I have escaped. I am safe within myself. I have made an order for myself, and no one can disturb it”.
} 
uma nota de cinco dólares, como se fosse uma esmola, após relatar rapidamente sua experiência com pessoas que fingiam ter alguma dificuldade com o intuito de ganhar dinheiro fácil. Entretanto, Marilyn mostrou-se compreensiva com o ponto de vista de Nazerman e humilde ao aceitar a doação, prevenindo-o de que voltaria à loja de penhores.

Algumas características se sobressaem em Marilyn, como o seu temperamento calmo e a sua capacidade de não fazer julgamentos precipitados. Em sua segunda abordagem a Nazerman, em busca de uma amizade ou companhia para um almoço, o penhorista se mostra mais rude e impaciente com ela. Ao ser questionado sobre a sua nacionalidade estrangeira, ele reage com certa agressividade no decorrer de sua resposta, com frases como: "você parece não ter qualquer senso de discrição, muito como uma criança tola que não tem nenhum instinto para a indisposição de seu ouvinte para falar"23 (WALLANT, 1961, p. 103) e "[v]olte na próxima semana e eu posso lhe dar mais algum [dinheiro]. Do contrário, eu não tenho nada para você" 24 (p. 103). Apesar de Marilyn sentir-se inicialmente humilhada com as palavras recebidas, ao perceber os números azuis tatuados no braço de Nazerman, a raiva pelo constrangimento pelo qual estava passando transformou-se em compaixão. Em vez de julgá-lo por suas palavras rudes, ela desculpou-se, mostrando novamente entender os motivos que o levavam a ter tal comportamento e insistindo em oferecer sua amizade.

Esse posicionamento de Marilyn demonstra, primeiramente, a sua aceitação à condição de Nazerman tal como ele é, sem impor condições e respeitando a sua individualidade. Em segundo lugar, Marilyn prova sua disposição para ouvir e, por isso, desempenha uma importante função no percurso de superação do trauma, pois encoraja constantemente o sobrevivente a falar, embora haja grande resistência por parte do protagonista, pois ele achava impossível para Marilyn entender o que ele estava passando: "[h]á um mundo tão diferente em escala que as emoções dele não suportam nenhuma semelhança com as suas; ele tem emoções em medidas tão diferentes que elas têm se tornado uma espécie diferente!" 25 (WALLANT, 1961, p. 146). É o medo do sobrevivente de não ter a sua experiência compreendida pelo ouvinte. No entanto, Marilyn vai desfazendo esse anseio de Nazerman ao demonstrar que é capaz de compreender sua experiência e, até mesmo, identificar-se com ela: "[e]u tenho alguma ideia do que você tem passado, senhor Nazerman"26 (WALLANT, 1961, p. 145).

No relato, o papel de ouvinte desempenhado por Marilyn Birchfield é muito importante para Nazerman, pois é através dessa aproximação entre ambos que se torna possível o resgate, ao menos em parte, da humanidade do personagem vitimado pelo trauma. O estudioso Dori Laub aponta alguns aspectos decisivos que cabem ao ouvinte em situações como as descritas no romance em questão. Segundo o autor, nesses casos, o ouvinte se torna um participante e um coautor do evento traumático, pois, por meio desse gesto de escuta inte-

\footnotetext{
23 Traduzido do original: "you seem to have no sense of discretion, much like a silly child who has no instinct for her listener's unwillingness to talk”.

24 Traduzido do original: "Come back next week and I may give some more. Otherwise, I have nothing for you".

25 Traduzido do original: "There is a world so different in scale that its emotions bear no resemblance to yours; it has emotions so different in degree that they have become a different species!".

26 Traduzido do original: "I have some idea of what you've been through, Mr. Nazerman".
} 
ressada, é como se ele revivesse o trauma da vítima. O ouvinte, ao interagir com os lamentos ou silêncios do sujeito, pode se tornar uma espécie de testemunha do ocorrido. Assim, ele deve respeitar o que é dito ou o que é silenciado pela vítima, de modo que se torne "uma companhia numa viagem para uma terra desconhecida, uma viagem que o sobrevivente não pode atravessar ou retornar sozinho" 27 (LAUB, 1992, p. 59). Nesse sentido, o pesquisador adverte que o ouvinte deve ser alguém dotado de habilidades e conhecimentos específicos para lidar com a situação, pois, se ele não o for, pode haver um retorno ao evento traumático. Laub destaca que o ouvinte deve ser sensível no reconhecimento de pistas deixadas pelo falante sobre seus desejos mais imediatos - falar, calar-se, chorar, etc. - para que a narrativa testemunhal se construa. Essas qualidades apontadas pelo psicanalista podem ser vistas no personagem Marilyn.

O início do renascimento de Sol Nazerman na narrativa pode ser percebido após o seu contato com Marilyn. Alguns episódios podem ser destacados no sentido de mostrar que ocorre uma mudança no seu comportamento rotineiro após conhecer e interagir com Marilyn. Primeiramente, Sol aceita o insistente convite dela para almoçar à beira de um rio. Durante esse almoço, Marilyn se mostra disposta a entender as dificuldades daqueles que a cercam e fala de sua própria solidão. Nesse ponto, Sol dá o seu sinal inicial de abertura para com ela e conta sobre sua dificuldade em dormir e como não tem se sentindo bem nos últimos tempos. Marilyn entende o sentido desse sinal e, apesar do comportamento fechado de Sol, é sensível para ver além da imagem que ele esperava transmitir: "[v]ocê baixou sua defesa por um momento e eu vi isso. [...] Eu estou começando a pensar que você está escondendo um ser humano sob sua conduta fria"28 (WALLANT, 1961, p. 142).

O segundo episódio que aponta para uma mudança de comportamento em Nazerman é quando ele começa a recusar o dinheiro de Murillio, pois, inicialmente, o penhorista não se importava com a origem do dinheiro que recebia. Todavia, mais tarde, ao saber que uma das fontes de dinheiro era uma casa de prostituição, começa a se perturbar profundamente a ponto de, por vezes, tentar se desvencilhar dele. Embora o dinheiro tivesse uma considerável importância para Sol, o penhorista passou a se sentir muito incomodado com a origem daquele dinheiro, pois não podia conceber que viesse da prostituição. Possivelmente isso se deva ao fato de que Nazerman testemunhou a humilhante condição de muitas mulheres que foram obrigadas a se prostituir ou que sofreram algum tipo de abuso sexual nos campos de concentração, incluindo sua esposa, e, por isso, não poderia mais ser condescendente com tal situação.

Um terceiro acontecimento que indica que Nazerman está lidando com o trauma e reencontrando sua humanidade diz respeito ao momento em que ele liga para Marilyn aceitando o convite para fazer um passeio de navio. Era época do aniversário da morte de sua família e Nazerman sentiu uma “insuportável solidão"29 (WALLANT, 1961, p. 205). Desejava chorar, mas era incapaz de fazer isso. Então, naquela manhã de domingo, já longe de sua

\footnotetext{
27 Traduzido do original: "a companion in a journey onto an uncharted land, a journey the survivor cannot traverse or return from alone".

28 Traduzido do original: "You were off your guard for a moment, and I saw it. [...] I'm beginning to think you're hiding a human being under your cold manner".

29 Traduzido do original: "unbearable loneliness".
} 
casa, o penhorista liga para Marilyn e combinam o passeio de barco. Este é um acontecimento marcante na trajetória de Nazerman, pois a sua atitude em relação a Marilyn indica que foi despertado nele, no mínimo, um sentimento de confiança em relação a ela. Esse é um acontecimento de destaque porque, pela primeira vez, o penhorista consegue retornar ao seu passado e narrar sobre ele com maior profundidade.

Um quarto indício de que Sol começa a resgatar a sua humanidade é a mudança de comportamento em relação a seus clientes. Acostumado a tratá-los com indiferença e desvalorizar seus bens, o penhorista começa a prestar atenção em suas histórias, entender suas necessidades e atribuir um pouco mais de valor aos objetos penhorados. Essa situação pode ser exemplificada quando Leopold traz um par de sapatos de bebê para penhorar e conta brevemente sua história para Sol, que parece muito tocado e pergunta ao seu cliente: "[q]uanto você quer?"30 (WALLANT, 1961, p. 251). Não era comum Sol perguntar aos seus clientes o valor que eles davam às suas mercadorias, antes, o penhorista atribuía o mínimo possível, sem se importar com suas reclamações.

Outro episódio marcante que traz à tona muitos dos sentimentos até então reprimidos em Nazerman é a morte de seu assistente Jesus Ortiz. Após planejar, com alguns comparsas, um assalto na loja de penhores, Ortiz é assassinado pelos próprios companheiros numa tentativa de proteger a vida de Nazerman. Ao ouvir a mãe de Ortiz lamentando a morte do filho, o penhorista se identifica com a sua dor e fica comovido: "enchendo os ouvidos do penhorista, inundando-o, afogando-o, arrastando ele de volta para o mar de lágrimas que ele pensou ter escapado. [...] Bom Deus, o que seria tudo isso? Amor? Poderia ser amor?"31 (WALLANT, 1961, p. 272). Nazerman sentiu-se confuso com os sentimentos que foram despertados com tal situação, pois acreditava estar seguro em seu mundo interior, imune a tudo e a todos que o cercavam. Porém, consegue dar vazão aos seus sentimentos e chorar. Ao se referir ao sofrimento da mãe de Ortiz, ele declara aos policiais: "[o] que ela quer de mim? Não pode ver que eu estou chorando por ela, que eu estou chorando por todos eles agora! [...] Então, talvez eu ame todos eles'. [...]. Então ele começou a chorar"32 (WALLANT, 1961, p. 277-278).

Com a morte de Ortiz, o penhorista vive novamente o trauma de perder subitamente alguém próximo a ele. Contudo, dessa vez, Nazerman não mais reprime a sua dor, antes, chora por Ortiz e por toda sua família morta durante o Holocausto. Era como se ele voltasse ao momento de sua perda, ouvindo "todos eles", todos que ele amava e morreram como prisioneiros nos campos de concentração, mas agora permitindo-se expressar a sua dor, chorar as suas perdas, enfim, viver o seu luto. Além do mais, Nazerman se desfaz de um sentimento comum, segundo Bruno Bettelheim, aos sobreviventes do Holocausto: o sentimento de culpa dos que sobreviveram (BETTELHEIM, 1989, p. 34). Após a morte de Ortiz, ao caminhar às margens do rio que era parte do seu trajeto, Nazerman resgatava suas memórias: "[n] a verdade, o penhorista estava contando as suas perdas e perdoando

\footnotetext{
30 Traduzido do original: "How much do you want?".

31 Traduzido do original: "filling the Pawnbroker's ears, flooding him, drowning him, dragging him back to that sea of tears he had thought to have escaped. [...] Good God, what was all this? Love? This could be love?".

32 Traduzido do original: "What does she want from me? Can't she see that I am weeping for her, that I am weeping for all of them now! [...] So maybe I love all of them'. [...] Then he began to cry".
} 
a si mesmo enquanto olhava o rio"33 (WALLANT, 1961, p. 279). Ele finalmente consegue perdoar-se da culpa irracional por não ter conseguido salvar sua família ou, simplesmente, por ter sobrevivido. Nesse momento, então, Sol vive o seu luto pelas mortes do presente e do passado: "[d]escansem em paz, Ortiz, Mendel, Rubin, Ruth, Naomi, David... descansem em paz,' ele disse, ainda chorando um pouco, mas mais para si mesmo"34 (WALLANT, 1961, p. 279).

Por fim, outro importante episódio enfatiza o percurso de Nazerman no caminho da superação do trauma. O protagonista esteve presente na hora da morte de Mendel, pai de Tessie. Esse foi um momento bastante difícil para ela, pois retornavam muitas memórias de tempos antigos e era necessário conforto e apoio. No entanto, inicialmente, Sol foi insensível ao dirigir-lhe as palavras: “' $[$ e] squeça tudo aquilo. Não pense, não sinta. [...] Não sofra, não tenha medo. [...] Enquanto isso, coma e descanse. Não preste atenção, não chore!'”35 (WALLANT, 1961, p. 229). Tamanha frieza causou perplexidade em Tessie, que, ao questionar Nazerman se poderia compartilhar com ele seu pranto, ainda ouviu: “[p]ara o inferno com seu choro"”36 (WALLANT, 1961, p. 230). Porém, no último parágrafo do romance, a narrativa expõe a mudança de comportamento de Nazerman em relação a Tessie. A indiferença do penhorista dá lugar à sensibilidade ao sofrimento dela, pois Nazerman "começou a caminhar para o metrô para tomar o longo e subterrâneo trajeto para a casa de Tessie, a fim de ajudá-la com seu luto"37 (WALLANT, 1961, p. 279).

Pela presente análise, evidencia-se que o primeiro receio que a vítima de um episódio traumático sente é o de não ser ouvida ou que a ela não seja dada a devida atenção ou importância no momento do relato. Entretanto, se essa primeira barreira é transposta, isto é, se o sobrevivente encontra alguém em quem possa confiar, ele vai se sentir seguro e, a partir daquele instante, pode começar um processo terapêutico que culminará no alívio da carga traumática. Em todo caso, é necessário um efetivo investimento do ouvinte para se estabelecer um testemunho e o início da cura da vítima. Ao que parece, Marilyn satisfaz um dos principais requisitos postos por Laub: o de ser "discretamente presente, durante todo o testemunho" ${ }^{38}$ (LAUB, 1992, p. 71). Ela se mantém muito respeitosa em relação a Nazerman e nunca interfere no seu relato. Embora ele nunca dê um testemunho completo sobre seu passado traumático, ele narra um dos episódios mais felizes de sua juventude: uma viagem de barco pelo rio Vistola em direção à cidade de Wyzgorod, na Polônia. Durante a fala de Sol, Marilyn se comporta exemplarmente: "Marilyn se sentou sem fazer qualquer movimento, seus lábios suavemente se abriram, seus olhos brilharam e fitaram o

\footnotetext{
33 Traduzido do original: "Actually, the Pawnbroker was counting his losses and forgiving himself as he watched the river".

34 Traduzido do original: “'Rest in peace, Ortiz, Mendel, Rubin, Ruth, Naomi, David... rest in peace, he said, still crying a little, but mostly for himself".

35 Traduzido do original: “Forget all that. Don't think, don't feel. [...] Don't suffer, don't fear. [...] Meanwhile, eat and rest. Don't pay attention, don't cry!’”.

36 Traduzido do original: “"To hell with your crying”".

37 Traduzido do original: “Then he began walking to the subway to take the long, underground journey to Tessie's house, to help her mourn".

38 Traduzido do original: "to be unobtrusively present, throughout the testimony".
} 
rosto estranhamente meigo do penhorista; ela manteve a sua calma como se temesse perfurar a superfície delicada da reminiscência dele"39 (WALLANT, 1961, p. 208).

O romance não aborda a total superação do trauma por Nazerman. Todavia, permite que se evidencie a possibilidade de mudanças de comportamento e de condutas mediante situações específicas. Se o protagonista vive atormentado pelas lembranças de um passado traumático, é porque perdeu a confiança em tudo e em todos à sua volta, algo que o impediu de externalizar a sua dor. É justamente essa não-externalização da dor vivida que faz com que a vítima fique presa ao seu passado, nutrindo sentimentos de culpa, medo, remorso e frieza emocional. Uma vez que não há a narração ou uma tentativa de narração do trauma, não há uma abertura para o sujeito "retramar" (WHITE, 1994, p. 103) a sua dor e, por isso, há uma fixação no trauma (FREUD, 1996) e, consequentemente, a sua não-superação. É o que aconteceu com Nazerman. Devido ao excesso de "real" que o acometeu no passado, este "supertramou" o seu discurso e, por um longo tempo, não conseguiu se desprender dele. No entanto, a partir do momento em que Nazerman começa a confiar em Marylin e, com isso, a externalizar a sua dor, inicia-se um processo terapêutico que culminará numa mudança de comportamento e emoções.

Por um longo tempo, Nazerman silenciou a sua dor. Se, por um lado, esse silenciamento funcionou como uma estratégia de defesa; por outro, contribuiu para que ele se mantivesse preso ao seu passado de dor. Ou seja, devido às dificuldades inerentes ao processo de rememoração de fatos que gostariam de esquecer, muitos sobreviventes optam por permanecer em silêncio. Essa escolha, aparentemente mais fácil, ocasiona um efeito devastador no equilíbrio psíquico da vítima. Assim, se o trauma não pode ser completamente superado, a vítima não tem dele o domínio necessário para decidir abandoná-lo em lugares escondidos da memória. A narrativa, nesse sentido, ajuda a vítima de um evento traumático a dar uma nova significação a sua dor e aprender a conviver de forma mais digna com as memórias de um passado de violência.

\section{REFERÊNCIAS}

ADORNO, Theodor. Educação após Auschwitz. In: COHN, Gabriel (Org.). Theodor W. Adorno: sociologia. Trad. Flávio R. Kothe, Aldo Onesti e Amélia Cohn. 2. ed. São Paulo: Ática, 1994. p. 33-45.

ARENDT, Hannah. Homens em tempos sombrios. Trad. Denise Bottmann. São Paulo: Companhia das Letras, 2008.

BENJAMIN, Walter. Conto e cura. In: Rua de mão única. Trad. Rubens Rodrigues Torres Filho e José Carlos Martins Barbosa. 5. ed. São Paulo: Brasiliense, 1995. p. 255-256.

O narrador: considerações sobre a obra de Nikolai Leskov. In: Magia e técnica, arte e política. Trad. Sergio Paulo Rouanet. 7. ed. São Paulo: Brasiliense, 1994. p. 197-221.

39 Traduzido do original: "Marilyn sat without moving, her lips slightly parted, her eyes bright and tender on the Pawnbroker's strangely softened face; she maintained her stillness as though she feared to puncture the delicate surface of his reminiscence". 
BETTELHEIM, Bruno. Sobrevivência e outros estudos. Trad. Maria Cristina Monteiro. Porto Alegre: Artes Médicas, 1989.

FREUD, Sigmund. Fixação em traumas - o inconsciente. In: Obras psicológicas completas de Sigmund Freud: edição standard brasileira. Trad. Jayme Salomão. Rio de Janeiro: Imago, 1996. Vol. XVI. p. 281-308.

Luto e melancolia. In: Obras psicológicas completas de Sigmund Freud: edição standard brasileira, 1996. Trad. Jayme Salomão. Rio de Janeiro: Imago, 1996. Vol. XIV. p. 249-263.

LAUB, Dori. Bearing Witness, or the Vicissitudes of Listening. In: ; FELMAN, Shoshana (Eds.). Testimony: Crises of Witnessing in Literature, Psychoanalysis and History. New York/ London: Routledge, 1992. p. 57-74.

LIMA, Luiz Costa. A aguarrás do tempo: estudos sobre a narrativa. Rio de Janeiro: Rocco, 1989.

WALLANT, Edward Lewis. The Pawnbroker. New York, London: A Harvest; HBJ Book, 1961.

WHITE, Hayden. O texto histórico como artefato literário. In: Trópicos do discurso: ensaios sobre a crítica da cultura. Trad. Alípio Correia de França Neto. 2. ed. São Paulo: Edusp, 2001. p. 97-116. 